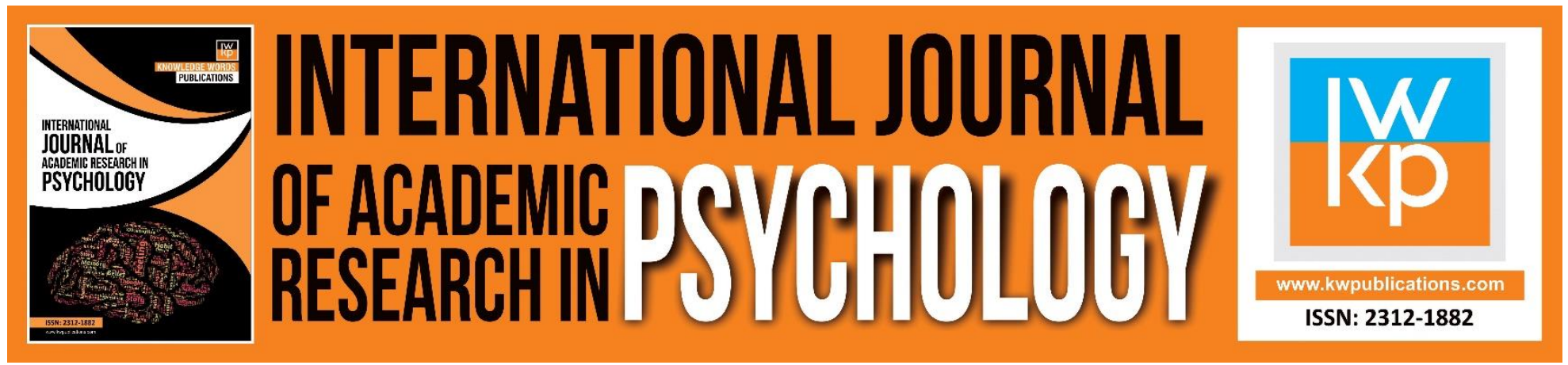

\title{
Combined Intervention for Caregivers of Patients with Dementia: A Randomized Controlled Trial
}

Konstantina Karagiozi, Vasileios Papaliagkas, Georgios Giaglis, Evridiki Papastavrou, Vassiliki Pattakou \& Magdalini Tsolaki

To Link this Article: http://dx.doi.org/10.46886/IJARP/v1-i1/1203 DOI:10.46886/IJARP/v1-i1/1203

Received: 09 January 2014, Revised: 22 March 2014, Accepted: 17 April 2014

Published Online: 27 April 2014

In-Text Citation: (Karagiozi et al., 2014)

To Cite this Article: Karagiozi, K., Papaliagkas, V., Giaglis, G., Papastavrou, E., Pattakou, V., \& Tsolaki, M. (2014). Combined Intervention for Caregivers of Patients with Dementia: A Randomized Controlled Trial. International Journal of Academic Research in Psychology, 1(1), 8-25.

\section{Copyright: (C) 2014 The Author(s)}

Published by Knowledge Words Publications (www.kwpublications.com)

This article is published under the Creative Commons Attribution (CC BY 4.0) license. Anyone may reproduce, distribute, translate and create derivative works of this article (for both commercial and non-commercial purposes), subject to full attribution to the original publication and authors. The full terms of this license may be seen at: http://creativecommons.org/licences/by/4.0/legalcode

Vol. 1, No. 1, 2014, Pg. 8 - 25

https://kwpublications.com/journals/journaldetail/IJARP JOURNAL HOMEPAGE

Full Terms \& Conditions of access and use can be found at https://kwpublications.com/pages/detail/publication-ethics 


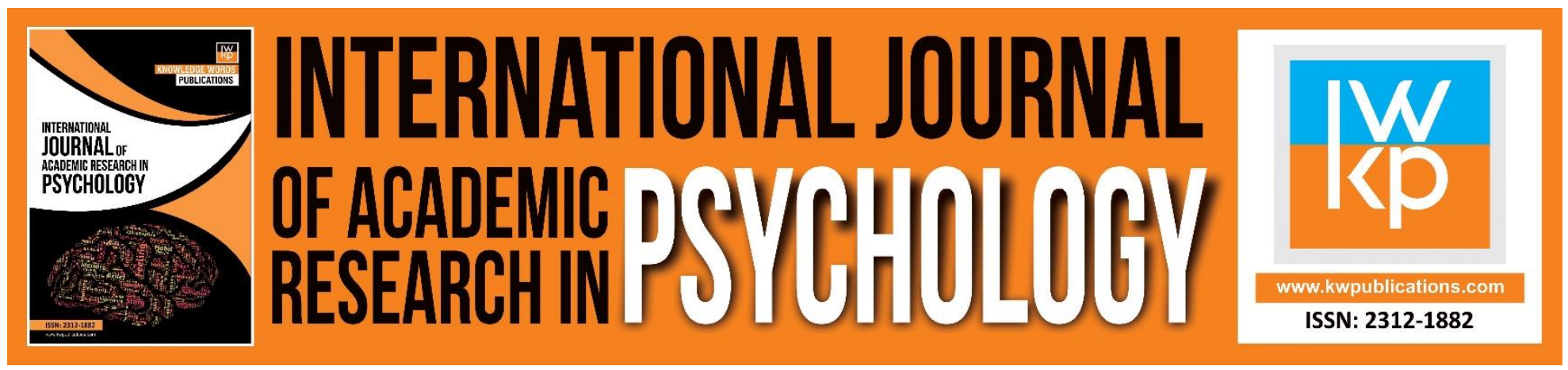

\title{
Combined Intervention for Caregivers of Patients with Dementia: A Randomized Controlled Trial
}

\author{
Konstantina Karagiozi ${ }^{1}$, Vasileios Papaliagkas², Georgios Giaglis ${ }^{1}$, \\ Evridiki Papastavrou ${ }^{3}$, Vassiliki Pattakou ${ }^{4} \&$ Magdalini Tsolaki ${ }^{1,2}$ \\ ${ }^{1}$ Hellenic Association of Alzheimer Disease and Related Disorders, Thessaloniki, Hellas, ${ }^{23} \mathrm{rd}$ \\ Department of Neurology, Faculty of Medicine, Aristotle University of Thessaloniki, Hellas, ${ }^{3} \mathrm{School}$ \\ of Health Sciences, Cyprus University of Technology, ${ }^{4}$ School of Social Work, TEl, Crete, Hellas
}

\begin{abstract}
Objectives: Caregivers of patients with dementia are at a greater risk of developing burden, strain and psychiatric morbidity in the form of depression. Psychotherapeutic interventions are essential in order to facilitate their role and improve their emotional state. This study presents a randomised controlled trial of a combined group intervention, including psychoeducational program and group psychotherapy intervention using Cognitive Behavioural Therapy, aiming to evaluate its effectiveness in psychological health of caregivers in Greece.
\end{abstract}

Method: Ninety seven caregivers were randomly allocated to an experimental group (58 participants) which participated in a 6-month programme- and a control group (54 participants) which did not receive any kind of intervention (was in a wait list). Psychosocial assessment was performed for anxiety, depression and burden.

Results: According to the analysis which was performed by protocol statistically significant differences were found between the experimental and the control group in levels of anxiety $[F(1.94)=20.94, p<0.001]$, depression $[F(1.94)=36.93, p<0.001]$ and sense of burden $[F(1.94)=51.44$, $p<0.001]$. The difference was in benefit of the experimental group.

Conclusion: Combined intervention for caregivers can have protective effects on their sense of burden, depression and anxiety symptoms.

Keywords: Cognitive-Behavioural Therapy, Psycho-Education, Caregivers, Dementia.

\section{Introduction}

Dementia is a serious neurodegenerative disease that affects functional and cognitive processes, resulting in progressive decline and deprivation of independence. During the course of the disease, the patient becomes disorientated and disorganized due to the manifested cognitive decline (Reitz, Brayne, \& Mayeux, 2011); this dysfunction has an immediate impact on caregivers, who are required to assist patients in daily activities from the early stages. As the disease progresses, the patient becomes even less independent and the role of the caregiver becomes gradually more 
INTERNATIONAL JOURNAL OF ACADEMIC RESEARCH IN PSYCHOLOGY

Vol. 1, No. 1, 2014, E-ISSN: 2312-1882 @ 2014 KWP

demanding. There is extensive research evidence supporting that it is very common for the caregivers to experience high levels of burden and psychological morbidity as well as social isolation, physical ill-health, poor quality of life, relational problems, family conflict, problems with employment and financial hardships (Connell, Janevic, \& Gallant, 2001; Etters, Goodall, \& Harrison, 2008; Brodaty \& Donkin, 2009; Jönsson \& Wimo, 2009; Van Vliet et al., 2010; Varela et al., 2011; Pinquart \& Sörensen, 2011).

Psychological morbidity, which includes depression and anxiety, has been clearly correlated with dementia caregiving in numerous studies (Gaugler et al., 2008). Rates of depression vary from $23 \%$ to $85 \%$ and of anxiety between $16 \%$ and $45 \%$ (Brodaty \& Donkin, 2009). A systematic review by Cuijpers (2005) reported that almost half of the caregivers develop a depressive disorder within a year. More recently Joling et al. (2012) found that from the 725 caregivers at risk, 180 (24.8\%) developed depression within a period of 18 months.

However, not all caregivers are influenced to the same degree. In their review of predictors of and protectors from caregiver distress, Brodaty and Donkin (2009) classify the caregiver variables in three categories; personality characteristics, perception and experience of the caregiving role and coping strategies. It has also been shown that caregiver strain depends strongly on the sense of burden, in addition to the impact that it has on their daily routine, which varies according to the coping strategies and social environmental support they receive (Papastavrou et al., 2007; Aneshensel et al., 2000; Kramer, 2000).

From the above it is obvious that the intervention in this group is essential on one hand in order to facilitate their role and reduce the likelihood of institutionalization for care recipients (Mittelman et al., 2008) and, on the other, to improve their emotional state and quality of life (Parker, Mills \& Abbey, 2008; Pinquart \& Sörensen, 2006; Sörensen, Pinquart, \& Duberstein, 2002; Schulz et al., 2002; Cooke et al., 2001). Interventions that have been applied extensively include: a) psychoeducation models b) stress management c) psychological support d) family counseling and e) models of combined techniques (Llanque \& Enriquez, 2012; Parker et al., 2008; Sörensen et al., 2006; Pinquart \& Sörensen, 2006; Acton \& Kang, 2001).

In particular, models that rely on psycho-educational components provide information on the symptoms and progression of the disease and on the effective management of the patient (Llanque \& Enriquez, 2012; Parker et al., 2008).

Furthermore, stress management techniques are designed to help caregivers develop coping strategies in order to optimize their coping efficacy. Usually, techniques are drawn from Cognitive Behaviour Therapy. Caregivers are trained to become more flexible, so they can deal with the changes that inevitably will come, find alternative solutions, learn to accept the current situation (GallagherThompson et al., 2010; Gallagher-Thompson et al., 2008; Selwood et al., 2007).

Models of psychological support target burden, so that the caregiver finds emotional support to deal with depression, anger, loneliness and loss (Gräbel et al., 2010; Chu et al., 2010).

Family counseling provides psychological support for all the members, either directly or indirectly involved. It helps to find more effective ways and facilitate communication by resolving conflict that may arise from caring for the patient. Additionally, it aims at strengthening the family bonds, so that all members participate equally to the care (Joling et al., 2012; Wang \& Chien, 2011; Mitrani et al., 2006). 
In more recent studies researchers report that they have designed multiple component interventions and have demonstrated better outcomes than those with single interventions (Callahan et al., 2006; Gitlin et al., 2003). Combined techniques models consist of a mixture of the above psychotherapeutic strategies. The criterion for designing of a psychosocial therapy with combined techniques is the need for psychological support on the part of the caregiver. Most combined interventions mentioned in literature include educational programs and practices of strategic management, which are based on the techniques of cognitive behavioural psychotherapy. Both interventions aim at reducing secondary stress factors and preventing stress (Mitrani et al., 2006; Secker \& Brown, 2005).

The present randomised controlled trial was designed to assess the effectiveness of a combined intervention- a group psychotherapy intervention using Cognitive-Behavioural threrapy (CBT) and a psychoeducational program intervention- in caregivers of patients with dementia. Group combined intervention aimed to help caregivers develop effective coping skills, manage their negative thoughts and feelings, and reinforce their sense of caregiving efficacy which in turn helped them to reduce depressive and anxiety symptoms.

The psychoeducational program was selected because it would be helpful for caregivers to learn about dementia and have realistic expectations about the disease process. It was, also, expected to help them in making difficult decisions about the care and treatment of their care receivers, and learn to be flexible in difficult situations. Their knowledge of the aspects of the disease and their own needs could encourage them to be involved more consciously in group psychotherapy intervention having specifics therapeutic targets. This aspect is in accordance with previous evidence, which suggest that the willingness to attend a support service increases significantly when the sense of "need of support" increases. Neither the age or gender of caregivers and patients, nor the duration of illness was a significant predictor for its utilization (Llanque \& Enriquez, 2012; Gräbel et al., 2010; Burks, Lund, \& Hill, 1991; Goodman, 1991). According to previous studies, the combination of a psychoeducational program and psychotherapeutic intervention was expected to be more effective in reducing caregiver stress and depression than an educational program alone (Gallagher-Thompson et al., 2001; Selwood et al., 2007). CBT was expected to help caregivers cope better with their own feelings, learn ways of problem solving, in order to deal with everyday problems, and reach towards the acceptance of the disease in their life.

We hypothesized that this combined intervention would be effective on caregivers' emotional well-being. In particular, our hypothesis was that the experimental group would be better protected against anxiety, depression and sense of burden compared to the control group, after attending the combined intervention.

\section{Method}

\section{Design and Procedure}

This was a randomised controlled trial with measurements at baseline and 6 months after intervention. Each participant was assessed before and after the 6-month period of the study by the same trained psychologist who was blind to the allocation of groups. Both the initial and the followup assessments comprised of the following scales: Beck Depression Inventory- II - BDI-II (Beck, Steer, \& Brown, 1996), Beck Anxiety Inventory - BAl (Beck et al., 1988) and Zarit Burden Interview (Zarit, Reever, \& Bach-Peterson, 1980). In the initial assessment, all caregivers had been interviewed about 
INTERNATIONAL JOURNAL OF ACADEMIC RESEARCH IN PSYCHOLOGY

Vol. 1, No. 1, 2014, E-ISSN: 2312-1882 @ 2014 KWP

the specific difficulties they faced on caring their relative and their individuals targets of their participation in the intervention.

\section{Ethical Considerations}

Ethical approval was obtained from the Scientific Committee of the Greek Association of Alzheimer's Disease and Related Disorders. This ensures that the ethical rights of the participants are respected and that the research is carried out according to the national and international ethical guidelines. These included respect of the participants' right i) of anonymity and confidentiality of personal data ii) informed consent and iii) to withdraw at any time and for whatever reason without their statutory rights being affected. All participants have signed a written consent.

Access approval in Family Units in day centers of the Alzheimer's Association was received from the president of Greek Association of Alzheimer's Disease and Related Disorders. For open centre for the protection of the elderly access approval was received from the operating manager of centre.

\section{Power Analysis}

The primary outcome of this study was caregivers' burden as measured by ZBI. A previous study in the Greek population of Alzheimer's caregivers has shown that the ZBI has a standard deviation of about 16 and a mean near 40 (Koutsampasopoulos et al., 2008). Assuming that the testretest correlation would be at least 0.3 after four months, and in order to be able to identify a difference of about 15\% (i.e. 6 points) in a 2 (pre-post) $\times 2$ (with/out intervention) design with power of 0.8 and $a=0.05$, approximately 90 participants were needed. Adding $20 \%$ for possible drop-outs lead to a number of 108 , i.e. 54 in each group. Since this was a simple randomization design, recruitment stopped when both groups reached the 54 patients limit.

\section{Participants}

All participants were primary caregivers of patients suffering from dementia in moderate stage and they were caring for their relative at home. Caregivers were recruited from Family Units in three day centers of the Alzheimer's Association and an open centre for the protection of the elderly. Exclusion criteria were the previous attendance in support and educational programs, the interruption of previous attendance, the presence of psychiatric disorders according to Diagnostic and Statistical Manual of Mental Disorders-Fourth Edition (DSM-IV, 1994) and the presence of severe depressive symptoms according to Beck Depression Inventory (BDI-II) (Beck et al., 1996), which is in line with DSM-IV depression criteria, that required treatment with antidepressants. The reason of the exclusion was to avoid influence with medication.

The initial number of participants included in the study was 112 caregivers. Simple randomization was used independently in each of the four sites to allocate the participants to the experimental group (58 participants: 44 females/14 males, range age 30-85 years, mean age (std): 56.31 (13.70) and to the control group (54 participants: 42 females/ 12 males, range age 33-86 years, mean age (std): 57.24 (14.46)). The experimental group attended a psychoeducational program and a group psychotherapy intervention for 6 months allocated into sessions, each lasting 90 minutes. The two interventions were performed on the same morning. There was a 30 minute break between sessions. None of the participants complained of fatigue and tiredness during the interventions, all 
of which were performed free of charge. The control group did not receive any form of psychological intervention but was on a waiting list. After the end of 6-months, they were included in the combined psychological intervention (Figure 1).

Seven caregivers of the experimental group did not complete the intervention program due to practical difficulties $(n=3)$, health problems $(n=2)$, lack of interest $(n=1)$, and no systematic attendance $(n=1)$. Eight caregivers from the control group did not participate in the follow up assessment because of lack of interest $(n=5)$, practical difficulties $(n=2)$ and health problems $(n=1)$. The drop-outs of both groups were older in age than the so-called completers but there was no significant difference in any other demographic variables or in the questionnaire scores.

Ninety seven caregivers ( 51 from the experimental and 46 from the control group) finally completed their participation in the study and underwent the second assessment. The gender, age, education and relationship of the participants to the patients with dementia are presented in Table 1 . The two groups were well matched regarding gender $(p=0.812)$ and age $(p=0.407)$; there was a slight difference in the relationship status $(p=0.287)$ and in the level of education $(p=0.002)$. Moreover, at baseline there were no group differences in terms of level of anxiety $(p=0.957)$, depression $(p=0.851)$ and sense of burden $(p=0.476)$. Both study participants could be defined as a non clinical group (Table 1). However, all differences were not significant when horizontal (spousal) and vertical (children) caregivers were compared individually between the two groups.

\section{Measures}

\section{Beck Depression Inventory-II (BDI-II)}

Depressive symptoms were measured by the Beck Depression Inventory- Second Edition (BDI-II) Long Form (Beck et al., 1996). The BDI-II is a 21-item self-report questionnaire. Participants respond to questions in relation to how they felt over the past week. The higher the score, the more serious the level of depression the instrument has detected. The BDI-II has good reliability and validity. It has strong internal consistency, with a coefficient alpha of 0.92 , and good one week test-retest reliability $(r=0.93, p<0.001)$. The Greek translation of BDI-II shows good internal consistency $(\alpha=0.86)$ (Baklavas et al., 2009).

\section{Beck Anxiety Inventory}

The caregiver's anxiety symptoms were assessed by the Beck Anxiety Inventory (BAI) (Beck et al., 1988). The anxiety subscale consists of 21 items, assessing whether and to what extent participants report subjective, somatic symptoms of anxiety or symptoms of panic disorder over the past week. Answer categories of the items range from 0 (not at all) to 3 (very much). Higher scores indicate more severe anxiety symptoms. The BAl showed high internal consistency $(\alpha=0.92)$ and test-retest reliability over 1 week, $r(81)=0.75$.

\section{Zarit Burden Interview}

The caregiver's burden was assessed by the Zarit burden interview (Zarit et al., 1980). The Zarit has 22 questions with four choices, ranging from 0 (never) to 4 (always) for each item. The total score (full score: 88) was used for the analyses. Higher scores indicate more severe sense of burden. It has a high internal consistency $(\alpha=0.91)$ and construct validity $(\alpha=0.79)$. The Greek translation of Zarit Burden scale shows excellent reliability ( $\alpha=0.93$ ) (Papastavrou et al., 2006). 
INTERNATIONAL JOURNAL OF ACADEMIC RESEARCH IN PSYCHOLOGY

Vol. 1, No. 1, 2014, E-ISSN: 2312-1882 @ 2014 KWP

\section{The Intervention Program}

For the needs of this study, we designed a combined intervention which was applied in Greece for the first time. It consisted of a) a weekly group Psychoeducational program (90 minutes) and b) a weekly group psychotherapy session using CBT (90 minutes). Sessions were always held in the morning, at the day centre. Participants attended 24 sessions of each program (6 months).

a) Psychoeducational program

The aim of the psychoeducational program was to provide information to caregivers regarding the disease and the functionality level of the patient, in addition to guidelines for more effective care. The seminars were given by trained professionals and included neurologists, clinical psychologists, cognitive psychologists, dentists, physicians, dieticians and social workers. The topics covered a broad range of 4 categories: 1) General information about dementia, 2) Issues about caregiving - difficulties faced by caregivers, 3) Problems and difficulties faced by care receivers and 4) Ways of coping.

Caregivers of the experimental group $(\mathrm{N}=51)$ were separated in two groups in order that each attending group to consist of 20-25 persons. This regime was selected because it facilitated their active involvement throughout the seminars, by asking questions regarding patients or themselves, sharing their experiences, providing guidance and supporting other caregivers. The intervention in two experimental groups was facsimiled and was applied by the same person.

b) CBT group (CBTg)

The research required a combination of CBT and the clinical practice guidelines for group psychotherapy. Table 4 shows the topics included in 24 group sessions. The topics were selected based on the international literature about chronic illnesses and the initial interviews of caregivers.

CBT was used in order to help the caregivers develop new ways of interpreting the situation they are dealing with, become aware of their thoughts, identify their dysfunctional beliefs and change them with rational ones. Along with changing dysfunctional thoughts, CBT was oriented towards particular targets and focused on problems that emerge from the disease, aiming at changing the caregivers' behaviour (Beck, 1976; Burns, 1981).

For the CBTg to be effective, clinical practice guidelines for group psychotherapy by American Group Psychotherapy Association (AGPA) were performed (Leszcz \& Kobos, 2008). These guidelines were used in order to plan, evaluate, modify, explicate and monitor the group therapy intervention in an evidence-based fashion. In particular, AGPA's clinical practice guidelines for group psychotherapy concerned the fields of creating successful therapy group, therapeutic factors and mechanisms, selection of participants, preparation and pre-group training, group development and process, therapist interventions, ethical practice and termination of group psychotherapy.

CBTgs included 7-8 caregivers. Group intervention was selected, because within the framework of a group, people have the opportunity to be acquainted with others having similar experiences and problems; this helps them express their feelings. Moreover, the therapeutic procedure assists them to communicate through active involvement and, thus, develop relationships, which will provide them support by decreasing feelings of isolation (Yost et al., 1986; Yalom, Brown, \& Bloch, 1975). CBTg was performed by an expert psychologist trained in CBT.

\section{Statistical Analysis}

The data were analyzed on a per-protocol basis, including only subjects that completed both evaluations, including the intervention for the experimental group. The questionnaires' internal 
consistency was measured using Cronbach's alpha. To test for the existence of pre-intervention differences in the two groups, t-tests, Fisher's exact tests and Kendall's tau-b were performed for quantitative, dichotomous and categorical variables, respectively. A multivariate analysis of variance (MANOVA) was performed as an initial overall investigation of the intervention's effect. The analysis of the three outcome variables at the post-intervention assessment consisted of a series of analyses of covariance (ANCOVA), introducing participants' pre-intervention scores (simple models) as well as possible confounding variables (extended models) as covariates. $F$ and partial eta-squared values were reported as measures of the effect size of the intervention. The level of statistical significance was set to $p=0.05$.

Simple regression analysis was performed to test the association between change of burden anxiety and depression with the intervention condition. The statistical package SPSS for Windows, version 8 was used for the statistical analyses.

\section{Results}

All three questionnaires used in this study (BAI, BDI, ZBI) had very high internal consistency, as measured by Cronbach's a coefficient ( $a=0.885,0.814$ and 0.888 , respectively).

The initial MANOVA showed that at least one of the three outcomes were significantly affected by the intervention program $[F(4.93)=3.198, p=0.017]$. The results of the following ANCOVAs are shown in table 2.

\section{Anxiety}

The ANCOVA revealed statistically significant differences between the experimental and the control group in this variable $[\mathrm{F}(1.94)=20.94, \mathrm{p}<0.001]$ with caregivers in the experimental group showing a lower mean score than caregivers in the control group. Repeating the analysis including education and relationship status as confounding variables did not change the significance of the intervention $[F(1.92)=16.43, p<0.001]$. Neither of the confounding variables had a significant effect on anxiety.

\section{Depression}

A significant effect of the intervention on the experimental group was observed compared to the control group $[F(1.94)=36.93, p<0.001]$. Inclusion of the education and the relationship status in the model did not affect the comparison $[F(1.92)=29.74, p<0.001]$.

ZBI

The Zarit Burden Interview was the assessment most influenced by the intervention as shown by the ANCOVA [F (1.94) $=51.44, p<0.001]$. Neither education nor relationship status had any significant effect on this result $[F(1.92)=43.50, p<0.001]$.

In order to investigate the association of change in burden, anxiety and depression with the intervention condition a simple regression analysis was computed. The results showed that intervention had a significant positive association with change in $Z B I\left(R^{2}=0.341\right)$ as well as with $B A I$ $\left(R^{2}=0.176\right)$ and $B D I$ change $\left(R^{2}=0.236\right)$, as seen in Table 3 .

\section{Discussion}

The aim of the current study was to assess the effectiveness of a combined psychological intervention in caregivers of dementia patients. We assumed that the intervention would have positive effects on experimental group, compared to the control group, protecting them from 
deterioration. Accordingly, the experimental group showed stability and tendency improvement on anxiety and depressive symptoms as well as on the sense of burden, whereas the control group showed deterioration in these factors. These results showed the positive effects of psychological interventions and are consisted with previous studies which indicate the effectiveness and the impact of this type of interventions on caregivers' psychological health (Chu et al., 2010; Mittelman et al., 2008; Mittelman \& Roth, 2004; Stolley, Reed, \& Buckwalter, 2002; Marriott et al., 2000).

The protective role of intervention is highlighted by the stability of experimental caregivers in non clinical ranges as well as the deterioration of control group. This worsening of the control group can be attributed to the fact that dementia is a rapidly progressive neurodegenerative disease. Therefore, a time period of six months, might be enough for the development of severe symptoms in the moderate stage dementia patients that were included in the current study. As it was mentioned in the introduction, the progress of dementia might affect the emotional health of the caregivers. Furthermore, previous studies indicate that caregivers in intervention groups were significantly less depressed (Chu et al., 2010; Mittelman et al., 2008; Pinquart \& Sorensen, 2006; Coon, Thompson, Steffen, Sorocco, \& Gallagher-Thompson, 2003; Hepburn, Tornatore, Center, \& Ostwald, 2001; Gallagher-Thompson et al., 2001) and experienced lower burden (Ko, Lee, \& Baumann, 2007; Pinquart \& Sorensen, 2006; Hepburn et al., 2001) than those in the control group. However, it should be pointed out that the research studies mentioned above were performed in participants that were in the clinical range for anxiety and depression.

In contrast to the above results, Hebert et al. (2003) has shown that an intervention based on stress appraisal, coping skills and behavioural management of the patients with dementia did not change depression, anxiety or burden in the intervention group compared to the control. Furthermore, according to a systematic review of Selwood et al. (2007) there was no difference in caregivers' depression or burden in interventions based on group behavioural therapy, supportive therapy or education. Only interventions based on teaching coping strategies, either individually or in a group, appeared to be more effective in caregiver's psychological health. In general, group interventions appeared less effective than individual interventions.

These results are in contrast with our result that has shown that intervention had protective role on sense of burden, depression and anxiety in the intervention group compared to the controls. The difference between these refuted results can be attributed to three reasons i) the type of intervention, ii) the duration of intervention, iii) the emotional state of the participants.

Type of intervention: combined interventions, defined in literature, have different forms of interventions such as psychoeducational, counseling, skills training and emotional support. There are many different types of interventions that can be used and this variability makes it very difficult for any trial to compare between them. In the current study we investigated a specific type of combined therapy, designed by our scientific team and tailored to specific problems and needs of caregivers about the difficulties of care of their relative, as they had mentioned in the initial interview. We hypothesize that the effectiveness of the intervention is attributed to the structured design of intervention based on individuals' targets of caregivers. This aspect is also reinforced by Brodaty, Roberts and Peters (1994) who concluded that interventions should be tailored to specific problems of individuals' caregivers. Moreover, a systematic review by Smits et al. (2007) suggested that research and practice should focus on the diversity of needs of different target groups. 
INTERNATIONAL JOURNAL OF ACADEMIC RESEARCH IN PSYCHOLOGY

Vol. 1, No. 1, 2014, E-ISSN: 2312-1882 @ 2014 KWP

Secondly, it has been found that the duration of intervention may affect the effectiveness of intervention. According to the literature (Dröes et al., 2004; Quayhagen \& Quayhagen, 2001; MonizCook et al., 1998), long-term support programs appeared more efficient than short-term programs. The duration of the intervention in the current study was 6 months ( 24 sessions) that is to our knowledge longer than all the other studies performed.

The emotional state of caregivers: One of the reasons that probably interpret the difference between these refuted results, can be attributed to emotional state of the participants. In the recent study, the participants were not in a clinical range as concerns the anxiety and depression (mild anxiety and depression symptoms) as well as they had a mild to moderate burden. The participants of others study were in clinical range. One interpretation is that, that kind of interventions and especially the psycho-education interventions, have better effects on caregivers when they had preventive role. We assumed that the knowledge about the progression and the symptoms of the disease, the acquisition of coping strategies, the management of negative feelings and the adjustment of important aspects of care such as enriching the support group network or making appropriate decisions about the care, can help caregivers to be ready for the future and more resistant. Therefore, it can have protective effects on them. CBT was appropriate method to cope with the above themes.

The effectiveness of CBT on caregivers' depression and burden has been shown in previous studies (Pinquart \& Sorensen, 2006). According to CBT's theory of depression, negative or dysfunctional automatic thoughts are primary in the change of depressed mood (Clark \& Beck, 1999). Cognitive behavioural interventions aim to detect, modify and correct automatic negative thoughts. Automatic thoughts would play a mediating role in the relationship between changes in dysfunctional attitudes and depressive symptoms. In CBTg sessions with caregivers, one of the main target was to identify and modify their automatic negative thoughts and their dysfunctional attitudes that concern themselves, their patients' behaviour and their self-efficacy above their caregiver role. Self -efficacy is one's perception for its abilities to cope through various situations (Bandura \& Adams, 1977). Selfefficacy correlates with depression (Gilliam \& Steffen, 2006) and anxiety (Bandura, 1988).

So, caregivers with less dysfunctional thoughts on the disease's progress and their role, and with high sense of self-efficacy are able to deal better with any caregiving difficulty, are more acceptable to any possible failure, and are able to protect themselves from any other consequence of dementia, such as depression and anxiety.

As concerns the result about the caregivers' burden, the research has showed that experimental caregivers remained in a mild to moderate stage, showing tendency improvement, whereas the control group turned to moderate to severe range of burden. This result is validated considering what burden is. Caregiver burden is a state of physical, emotional, and mental exhaustion that can be caused from objective factors such as the patient's cognitive impairment and functional disability, as well as from subjective factors such as caregivers perceived situational control, perceived role conflict, positive appraisal and coping strategies (Pearlin et al., 1990). The sense of burden mirrors the subjective difficulties as well as the emotional state of the caregiver. According to recent studies about dementia caregivers, the development of coping strategies as well as anger, depression and stress management, establishes the sense of control and self-efficacy in the caregiver's skills that reduce depressive feelings and the sense of burden (Selwood et al., 2007; Coon et al., 2003). The studies of Papastavrou et al. (2007); Papastavrou et al. (2011) further showed that 
burden is related to specific coping strategies, as low-burden caregivers used more positive coping strategies such as problem solving and seeking social support than the more burdened ones.

To conclude, this study shows that 6-month group intervention that combines a psychoeducational program with group psychotherapy using CBT can have protective effects on caregivers' sense of burden, depression and anxiety symptoms, whereas in the control group the symptoms of depression, anxiety and sense of burden were increased; a finding that supports our hypothesis for the significance of CBT.

These conclusions should be interpreted very cautiously due to some limitations of the current study. First of all, the small size of the participant sample limits the generalizability of the results. Furthermore, no follow-up after six months was performed, which is in the authors' plans to be performed in another study. Another limitation is the lack of details of the patients' neuropsychological profile. Patients, whose caregivers participated in the study, had the diagnosis of moderate stage of dementia but their clinical examination was not available. One other limitation of the study, is that recent appropriate measures of caregivers distress such as Dysfunctional Thoughts about Caregiving Questionnaire were not administered in the study participants and basic measures such as the Zarit scale were selected. The lack of a measure about the dysfunctional thoughts is a limitation of the study because of the important role they play in the CBT.

In spite of these limitations, the present study has several implications for future investigations. Further research with a large size is needed to evaluate the efficacy of the present combined intervention on caregivers with patients in early, mediate and severe stage of dementia. Furthermore, it will be interesting to examine further outcomes other than depression, anxiety and burden, such as dysfunctional thoughts, coping skills and self-efficacy. Also, it should try to evaluate some interesting aspects of this approach, such as 'which is the most effective factor of this combined intervention?', 'what are the preferred participant characteristics?' and 'which is the preferred intervention duration?' towards a more effective intervention.

\section{Acknowledgments}

The authors thank Margaritidou Petrina, Blachou Axilleas, Feggarou Christina and Chatziioannou Maria for the data selection.

\section{Corresponding Author}

Konstantina Karagiozi

Hellenic Association of Alzheimer Disease and Related Disorders

Hellas

Address: 13 P. Sindika Street, Analipsi, Thessaloniki, P.C. 54643

Email: dinakaragiozi@gmail.com

\section{References}

Acton, G. J., \& Kang, J. (2001). Interventions to reduce the burden of caregiving for an adult with dementia: a meta-analysis. Research in Nursing \& Health, 24 (5), 349-360.

Aneshensel, C. S., Pearlin, L. I., Mullan, J. T., Zarit, S. H., \& Whitlatch, C. J. (1995). Profiles in caregiving: The unexpected career. San Diego: Academic Press. 
INTERNATIONAL JOURNAL OF ACADEMIC RESEARCH IN PSYCHOLOGY

Vol. 1, No. 1, 2014, E-ISSN: 2312-1882 @ 2014 KWP

Baklavas, G., Kosmidis, M., Giannakou, M., \& Roussi, P. (2009). Data analysis Depression Scale in clinical population. Paper presented at the 5th PanHellenic Data Analysis Conference, Rethimno, Crete.

Bandura, A. (1988). Self-efficacy conception of anxiety. Anxiety Research, 1, 77-98.

Bandura, A., \& Adams, N. E. (1977). Analysis of self-efficacy theory of behavioral change. Cognitive Therapy and Research, 1, 287-310.

Beck, A. T. (1976). Cognitive Therapy and the Emotional Disorders. New York.

Beck, A. T., Epstein, N., Brown, G., \& Steer, R. A. (1988). An inventory for measuring clinical anxiety: psychometric properties. Journal of consulting and clinical psychology, 56 (6), 893-897.

Beck, A. T., Steer, R. A., \& Brown, G. K. (1996). The Beck Depression Inventory Second Edition Manual. San Antonio: Psychological Corporation.

Brodaty, H., \& Donkin, M. (2009). Family caregivers of people with dementia. Dialogues in Clinical Neuroscience, 11(2), 217-28.

Brodaty, H., Roberts, K., \& Peters, K. (1994). Quasi-experimental evaluation of an educational model for dementia caregivers. International Journal of Geriatric Psychiatry, 9(3), 195-204.

Burns, D. (1981). Feeling good: The new mood therapy. New York: New American Library.

Burks, V., Lund, D., \& Hill, R. (1991). Factors associated with attendance at caregiver support group meetings. Activities, Adaptation \& Aging, 15, 93-108.

Callahan, C. M., Boustani, M. A., Unverzagt, F. W., Austrom, M. G., Damush, T. M., Perkins, A. J., Fultz, B. A., Hui, S. L., Counsell, S. R., \& Hendrie, H. C. (2006). Effectiveness of collaborative care for older adults with Alzheimer disease in primary care: a randomized controlled trial. JAMA : the journal of the American Medical Association, 295(18), 2148-2157.

Chu, H., Yang, C. Y., Liao, Y. H., Chang, L. I., Chen, C. H., Lin, C. C., \& Chou, K. R. (2010). The effects of support group on dementia caregivers' burden and depression. Journal of Aging and Health, 23(2), 228-241.

Clark, D. A., \& Beck, A. T. (1999). Cognitive theories and therapy. London: Cambridge University Press.

Connell, C. M., Janevic, M. R., Gallant, M. P. (2001). The costs of caring: impact of dementia on family caregivers. Journal of geriatric psychiatry and neurology, 14(4) 179-87.

Cooke, D. D., McNally, L., Mulligan, K. T., Harrison, M. J., \& Newman, S. P. (2001). Psychosocial interventions for caregivers of people with dementia: systematic review. Aging \& Mental Health, 5, 120-135.

Coon, D. W., Thompson, L., Steffen, A., Sorocco, K., \& Gallagher-Thompson, D. (2003). Anger and depression management: psychoeducational skill training interventions for women caregivers of a relative with dementia. The Gerontologist, 43(5), 678-89.

Cuijpers, P. (2005). Depressive disorders in caregivers of dementia patients: a systematic review. Aging Mental Health, 9(4), 325-30.

Diagnostic and Statistical Manual of Mental Disorders-Fourth Edition (DSM IV). (1994). International Classification of Diseases. World Health Organization.

Dröes, R., Meiland, F., Schmitz, M., Van Tilburg, W. (2004). Effect of combined support for people with dementia and caregivers versus regular day care on behaviour and mood of persons with dementia: results from a multi-centre implementation study. International Journal of Geriatric Psychiatry, 19, 673-684. 
INTERNATIONAL JOURNAL OF ACADEMIC RESEARCH IN PSYCHOLOGY

Vol. 1, No. 1, 2014, E-ISSN: 2312-1882 @ 2014 KWP

Etters, L., Goodall, D., \& Harrison, B. E. (2008). Caregiver burden among dementia patient caregivers: a review of the literature. Journal of the American Academy of Nurse Practitioners, 20 (8), 4238.

Gallagher-Thompson, D., Arean, P., Rivera, P., \& Thompson, L. W. (2001). A psychoeducational intervention to reduce distress in Hispanic family caregivers: results of a pilot study. Clinical Gerontology, 23(1-2), 17-32.

Gallagher-Thompson, D., Gray, H. L., Dupart, T., Jimenez, D., \& Thompson, L. W. (2008). Effectiveness of cognitive/behavioral small group intervention for reduction of depression and stress in Non-Hispanic White and Hispanic/Latino women dementia family caregivers: outcomes and mediators of change. Journal of Rational-Emotive \& Cognitive-Behavior Therapy, 26(4), 286303.

Gallagher-Thompson, D., Wang, P. C., Liu, W., Cheung, V., Peng, R., China, D., \& Thompson, L. W. (2010). Effectiveness of a psychoeducational skill training DVD program to reduce stress in Chinese American dementia caregivers: Results of a preliminary study. Aging \& Mental Health, 14(3), 263-273.

Gaugler, J. E., Pearlin, L. I., Davey, A., \& Zarit, S. H. (2000). Modelling caregiver adaptation over time: The longitudinal impact of behaviour problems. Psychology and Aging, 15, 437-450.

Gilliam, C. M., \& Steffen, A. M. (2006). The relationship between caregiving self-efficacy and depressive symptoms in dementia family caregivers. Aging \& Mental Health, 10(2), 79-86.

Gitlin, L. N., Belle, S. H., Burgio, L. D., Czaja, S. J., Mahoney, D., Gallagher-Thompson, D., Burns, R., Hauck, W. W., Zhang, S., Schulz, R., Ory, M. G., \& REACH Investigators. (2003). Effect of multicomponent interventions on caregiver burden and depression: the REACH multisite initiative at 6-month follow-up. Psychology and aging, 18(3) 361-74.

Goodman, S. (1991). Patterns of participation in support groups for dementia caregivers. Clinical Gerontologist, 10, 23-34.

Gräbel, E., Trilling, A., Donath, C., \& Luttenberger, K. (2010). Support groups for dementia caregivers - Predictors for utilization and expected quality from a family caregiver's point of view: A questionnaire survey PART I. BMC Health Services Research, 10(219).

Hepburn, K. W., Tornatore, J., Center, B., \& Ostwald, S. W. (2001). Dementia family caregiver training: affecting beliefs about caregiving and caregiver outcomes. Journal of the American Geriatrics Society, 49 (4), 450-457.

Joling, K. J., Van Marwijk, H. W., Smit, F., Van der Horst, H. E., Scheltens, P., Van De Ven, P. M., Mittelman, M. S., Van Hout, H. P. (2012). Does a family meetings intervention prevent depression and anxiety in family caregivers of dementia patients? A randomized trial. PLoS One. 7(1), e30936.

Jönsson, L., \& Wimo, A. (2009). The cost of dementia in Europe: a review of the evidence, and methodological considerations. Pharmacoeconomics, 27(5), 391-403.

Ko, S. H., Lee, M. C., \& Baumann, S. L. (2007). Reducing the burden of dementia in Korea. Nursing Science Quarterly, 20, 178-182.

Koutsampasopoulos, K., Ralli, F., Gavana, M., \& Benos, A. (2008). Psychiatric morbidity and burden among caregivers: a cross sectional study in rural north Halkidiki (Greece). Annals of General Psychiatry, 7(1), 124. 
INTERNATIONAL JOURNAL OF ACADEMIC RESEARCH IN PSYCHOLOGY

Vol. 1, No. 1, 2014, E-ISSN: 2312-1882 @ 2014 KWP

Kramer, B. J. (2000). Husbands caring for wives with dementia: A longitudinal study of continuity and change. Health and Social Work, 25(2), 97-107.

Leszcz, M., \& Kobos, J. C. (2008). Evidence-based Group Psychotherapy: Using AGPA's Practice Guidelines to Enhance Clinical Effectiveness. Journal of clinical psychology: In session, 64 (11), 1238-1260.

Llanque, S. M., \& Enriquez, M. (2012). Interventions for Hispanic Caregivers of Patients with Dementia: A Review of the Literature. American Journal of Alzheimer's Disease \& Other Dementias, 27 (1), 23-32.

Marriott, A., Donaldson, C., Tarrier, N., \& Burns, A. (2000). Effectiveness of cognitive-behavioural family intervention in reducing the burden of care in caregivers of patients with Alzheimer's disease. The British journal of psychiatry: the journal of mental science, 176, 557-562.

Mitrani, V. B., Lewis, J. E., Feaster, D. J., Czaja, S. J., Eisdorfer, C., Schulz, R., \& Szapocznik, J. (2006). The role of family functioning in the stress process of dementia caregivers. Gerontologist, 46(1), 97-105.

Mittelman, M. S., Brodaty, H., Wallen, A. S., \& Burns, A. (2008). Caregivers benefit from counseling. American Journal of Geriatric Psychiatry, 16(11), 893-904.

Mittelman, M., \& Roth, D. L. (2004). Sustained benefit of supportive intervention for depressive symptoms in caregivers of patients with Alzheimer's disease. The American Journal of Psychiatry, 161(5), 850.

Papastavrou, E., Kalokerinou-Anagnostopoulou, A., Alevizopoulos, G., Papacostas, S., Tsangari, H., \& Sourtzi, P. (2006). The validity and reliability of the Zarit burden interview in Greek Cypriot caregivers of patients with dementia. Nosileftiki, 45(4), 439-449.

Papastavrou, E., Kalokerinou, A., Papacostas, S. S., Tsangari, H., \& Sourtzi, P. (2007). Caring for a relative with dementia: family caregiver burden. Journal of Advanced Nursing. 58(5), 446-457.

Papastavrou, E., Tsangari, H., Karayiannis, G., Papacostas, S., Efstathiou, G., \& Sourtzi, P. (2011). Caring and coping: the dementia caregivers. Aging Mental Health, 15(6), 702-11.

Parker, D., Mills, S., \& Abbey, J. (2008). Effectiveness of interventions that assist caregivers to support people with dementia living in the community: a systematic review. International journal of evidence-based healthcare, 6(2), 137-172.

Pearlin, L., Mullan, J., Semple, S., \& Skaff, M. (1990). Caregiving and the stress process: An overview of concepts and their measures. The Gerontologist, 30(5), 583-594.

Pinquart, M., \& Sörensen, S. (2006). Helping caregivers of persons with dementia: which interventions work and how large are their effects? International Psychogeriatrics, 18(4), 577595.

Pinquart, M., \& Sörensen, S. (2011). Spouses, adult children, and children-in-law as caregivers of older adults: a meta-analytic comparison. Psychology and aging, 26(1), 1-14.

Quayhagen, M. P., \& Quayhagen, M. (2001). Testing of a cognitive stimulation intervention for dementia caregiving dyads. Neuropsychological Rehabilitation, 11, 319-332.

Reitz, C., Brayne, C., \& Mayeux, R. (2011). Epidemiology of Alzheimer disease. Nature reviews. Neurology, 7(3), 137-152.

Schulz, R., O'Brien, A., Czaja, S., Ory, M., Norris, R., Martire, L. M., Belle, S. H., Burgio, L., Gitlin, L., Coon, D., Burns, R., Gallagher-Thompson, D., \& Stevens, A. (2002). Dementia caregiver intervention research: in search of clinical significance. The Gerontologist, 42(5), 589-602. 
Secker, D. L., \& Brown, R. G. (2005). Cognitive behavioural therapy (CBT) for caregivers of patients with Parkinson's disease: a preliminary randomised controlled trial. Journal of Neurology, Neurosurgery, and Psychiatry, 76(4), 491-497.

Selwood, A., Johnston, K., Katona, C., Lyketsos, C., \& Livingston, G. (2007). Systematic review of the effect of psychological interventions on family caregivers of people with dementia. Journal of Affective Disorders, 101, 75-89.

Smits, C. H., De Lange, J., Dröes, R. M., Meiland, F., Vernooij-Dassen, M., \& Pot, A. M. (2007). Effects of combined intervention programmes for people with dementia living at home and their caregivers: a systematic review. International journal of geriatric psychiatry, 22(12), 11811193.

Sörensen, S., Duberstein, P., Gill, D., \& Pinquart, M. (2006). How effective are interventions with caregivers? An updated meta-analysis. The Gerontologist, 42, 356-372.

Sörensen, S., Pinquart, M., Duberstein, P. (2002). Dementia care: mental health effects, intervention strategies, and clinical implications. Lancet Neurology, 5(11), 961-973.

Stolley, J., Reed, D., \& Buckwalter, K. C. (2002). Caregiving appraisal and interventions based on the progressively lowered threshold model. American Journal of Alzheimer's Disease and Other Dementias, 17(2), 110-120.

Van Vliet, D., De Vugt, M. E., Bakker, C., Koopmans, R. T., \& Verhey, F. R. (2010). Impact of early onset dementia on caregivers: a review. International journal of geriatric psychiatry, 25(11), 10911100.

Varela, G., Varona, L., Anderson, K., \& Sansoni, J. (2011). Alzheimer's care at home: a focus on caregivers strain. Professioni infermieristiche, 64(2), 113-7.

Wang, L. Q., \& Chien, W. T. (2011). Randomised controlled trial of a family-led mutual support programme for people with dementia. Journal of clinical nursing, 20(15-16), 2362-2366.

Yalom, I., Brown, S., \& Bloch, S. (1975). The written summary as a group psychotherapy technique. Archives of general psychiatry, 32(5), 605-613.

Yost, E. B., Beutler, L. E., Corbishley, M. A., \& Allender, J. R. (1987). Chapter 2: The Structure of Group Cognitive Therapy with Older Adults. In Group Cognitive Therapy: A treatment Approach for Depressed Older Adults (14- 29). New York: Pergamon Press.

Zarit, S. H., Reever, K. E., \& Bach-Peterson, J. (1980). Relatives of the impaired elderly: correlates of feelings of burden. The Gerontologist, 20(6), 649-655. 
INTERNATIONAL JOURNAL OF ACADEMIC RESEARCH IN PSYCHOLOGY

Vol. 1, No. 1, 2014, E-ISSN: 2312-1882 @ 2014 KWP

\section{Appendix}

Fig.1. Participant's flow from $1^{\text {st }}-2^{\text {nd }}$ assessment

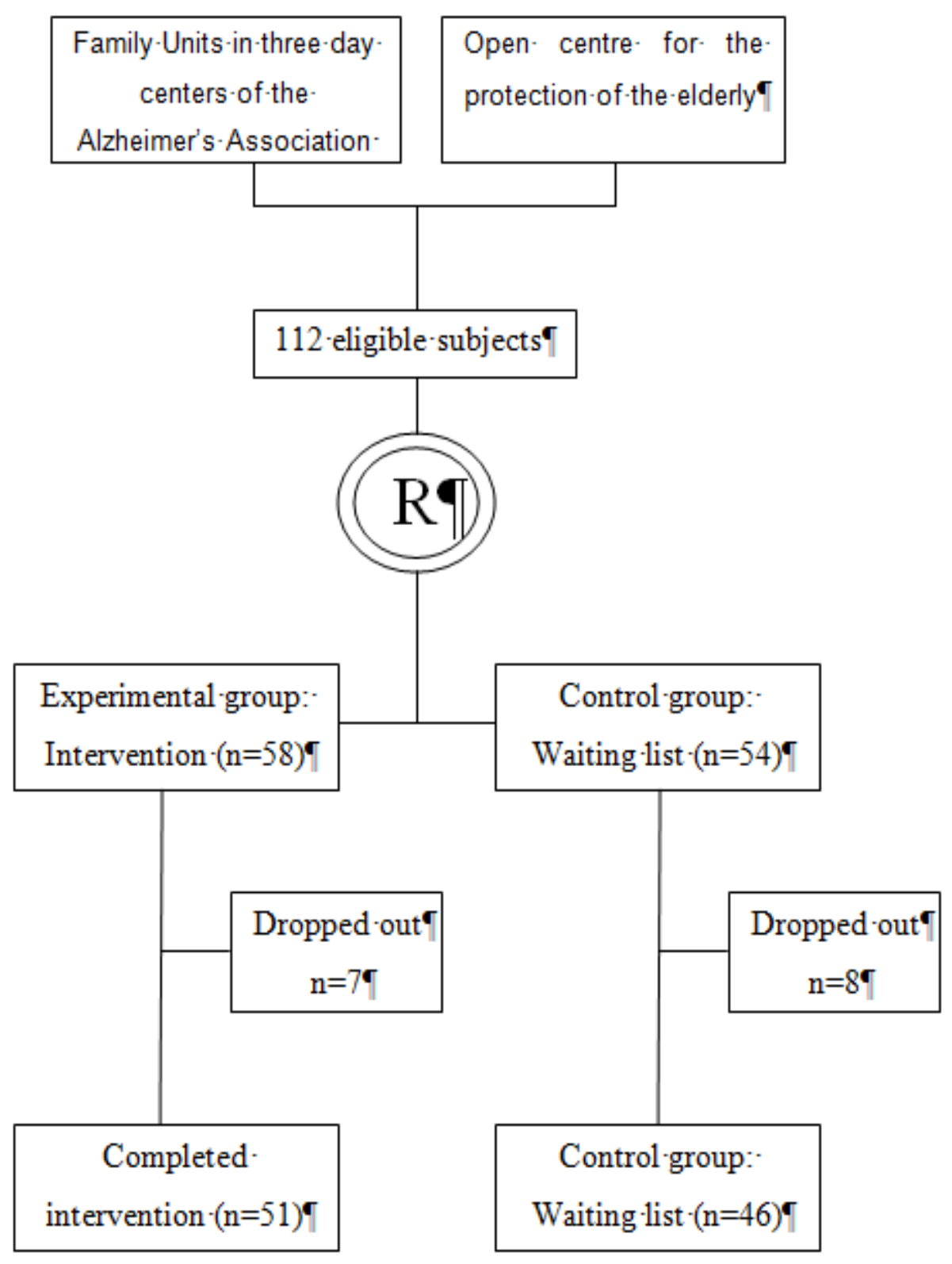


INTERNATIONAL JOURNAL OF ACADEMIC RESEARCH IN PSYCHOLOGY Vol. 1, No. 1, 2014, E-ISSN: 2312-1882 @ 2014 KWP

Table 1. Demographic characteristics and difference of performance between the two groups at baseline of participants

\begin{tabular}{|l|l|l|l|l|}
\hline & $\begin{array}{l}\text { Exp. group } \\
(\mathrm{n}=51)\end{array}$ & Ctrl. group (n=46) & Test statistic & $\begin{array}{c}\mathrm{p} \text { (two- } \\
\text { sided) }\end{array}$ \\
\hline Caregivers & & & & \\
\hline Sex, $\mathrm{n}(\%)$ & & & Fisher's Exact & 0.812 \\
\hline- Male & $11(21.6)$ & $11(23.9)$ & & \\
\hline -Female & $40(78.4)$ & $35(76.1)$ & & \\
\hline Mean age (std) & $54.18(12.44)$ & $56.48(14.77)$ & $\mathrm{t}^{95}=-0.833$ & 0.407 \\
\hline Education years (std) & $12.69(4.14)$ & $9.91(4.59)$ & $\mathrm{t}^{95}=-3.131$ & 0.002 \\
\hline Relationship, $\mathrm{n}(\%)$ & & & Fisher's Exact & 0.287 \\
\hline -Spouse & $15(29.4)$ & $19(41.3)$ & & \\
\hline -Child & $36(70.6)$ & $27(58.7)$ & & \\
\hline BAI & $8.57(6.65)$ & $8.65(8.52)$ & $\mathrm{t}^{95}=0.054$ & 0.957 \\
\hline BDI & $10.43(7.12)$ & $10.70(6.66)$ & $\mathrm{t}^{95}=0.188$ & 0.851 \\
\hline ZARIT & $39.55(17.45)$ & $37.20(14.60)$ & $\mathrm{t}^{95}=-0.716$ & 0.476 \\
\hline
\end{tabular}

BAI, BDI, ZARIT scores:Means ( \pm SD)

Footnotes

BAl: Beck Anxiety Inventory

BDI: Beck Depression Inventory

ZARIT: Zarit Burden Interview

Table 2. Differences of performance between the two groups after the intervention

\begin{tabular}{|l|l|l|l|l|l|l|}
\hline Variable & \multicolumn{2}{|l|}{ Post - intervention } & Adjusted values & $\begin{array}{l}\text { Effect } \\
\text { value (F) }\end{array}$ & $P$ & $\begin{array}{l}\text { Effect } \\
\text { size }\left(\eta^{2}\right)\end{array}$ \\
\hline & Exp. group & Ctrl. group & Exp./Ctrl. group & & & \\
\hline BAI & $7.25(7.00)$ & $14.20(11.85)$ & $7.29 / 14.16$ & 20.94 & 0.001 & 0.182 \\
\hline BDI & $6.76(5.20)$ & $13.67(8.40)$ & $6.84 / 13.59$ & 36.93 & 0.001 & 0.282 \\
\hline ZARIT & $35.57(14.77)$ & $46.85(16.42)$ & $34.69 / 47.82$ & 51.44 & 0.001 & 0.354 \\
\hline
\end{tabular}

BAI, BDI, ZARIT scores:Means ( \pm SD)

Table 3. Association of change in burden, anxiety and depression with the intervention condition

\begin{tabular}{|l|l|l|l|l|l|}
\hline Dpt. variable & Indpt. Variable & $\beta$ & $\mathrm{t}$ & $\mathrm{p}$ & $\mathrm{R}^{2}$ \\
\hline ZBI change & intervention & 0.584 & 7.01 & 0.001 & 0.341 \\
\hline BAl change & intervention & 0.420 & 4.51 & 0.001 & 0.176 \\
\hline BDI change & intervention & 0.485 & 5.41 & 0.001 & 0.236 \\
\hline
\end{tabular}


INTERNATIONAL JOURNAL OF ACADEMIC RESEARCH IN PSYCHOLOGY

Vol. 1, No. 1, 2014, E-ISSN: 2312-1882 @ 2014 KWP

Table 4. Content of CBTg

\begin{tabular}{|c|c|}
\hline & Content \\
\hline Session 1 & $\begin{array}{l}\text { Welcome, introduction and targets of the intervention } \\
\text { Confidentiality } \\
\text { Specific targets of caregivers }\end{array}$ \\
\hline Sessions 2-3 & $\begin{array}{l}\text { Focus on patients with dementia and relationship with them (past, } \\
\text { present, future) }\end{array}$ \\
\hline Sessions $4-6$ & $\begin{array}{l}\text { Focus on caregivers' role } \\
\text { Perceptions and thoughts about care and their role } \\
\text { Sense of effectiveness }\end{array}$ \\
\hline Session 7 & $\begin{array}{l}\text { Discussion about their social support network } \\
\text { Developing communication skills }\end{array}$ \\
\hline Sessions 8 & $\begin{array}{l}\text { Feedback about group process and personal development } \\
\text { Sharing impressions about others }\end{array}$ \\
\hline Sessions 9-11 & $\begin{array}{l}\text { Anxiety management } \\
\text { Teaching coping strategies } \\
\text { Problem solving }\end{array}$ \\
\hline Sessions $12-14$ & Coping with anger, guilt and defeat \\
\hline Sessions $15-16$ & Making difficult decisions, self-efficacy \\
\hline Sessions $17-23$ & $\begin{array}{l}\text { Focus on the acceptance of disease (redefinition of their personal } \\
\text { goals and life expectations, integration of disease in their life with } \\
\text { functional way and awareness of their role) }\end{array}$ \\
\hline Session 24 & $\begin{array}{l}\text { Discussion about achieved goals } \\
\text { Thoughts and feelings about procedure and group members }\end{array}$ \\
\hline
\end{tabular}

